\title{
FIAMA FIANDEIRA: O FASCÍNIO PELO HERMETISMO
}

\author{
Cinda Gonda ${ }^{1}$
}

À minha irmã, Angela Amália, in memoriam, a mais bela e corajosa tecelã.

\section{RESUMO}

As estratégias de leitura de um poema, como as definiu, ainda nos anos 1980, o crítico português Eduardo do Prado Coelho, a que se soma um projeto de abordagem textual "ao rés do chão", como a deseja Jorge Fernandes da Silveira, constituem os pontos de partida teóricos para encontrar a via de leitura da poesia de Fiama Hasse Pais Brandão e do seu fascínio pelo hermetismo. Numa segunda etapa, este ensaio gostaria de propor, juntamente com António Ramos Rosa, que a opção pelo hermetismo é a marca central da poesia contemporânea, o que permite em consequência recuperar aquele elo perdido entre a poesia de Orpheu e os poetas do grupo Poesia 61.

PALAVRAS-CHAVE: Fiama Hasse Pais Brandão, António Ramos Rosa, Árvore, hermetismo, poesia contemporânea.

\section{ABSTRACT}

The strategies of reading a poem, as defined in the 1980s, by the Portuguese critic Eduardo do

1 Professora de Literatura Portuguesa na Faculdade de Letras da Universidade Federal do Rio de Janeiro. E-mail: cgonda21@terra.com.br.

Recebido em: 15/06/2018

Aceito em: 01/07/2018

Diadorim, Rio de Janeiro, vol. 20, n. 1, p, 96-104, jan-jun. 2018. 
Prado Coelho, which includes a project of aprocching the text " closely", as Jorge Fernandes da Silveira wants it to be, are the theoretical starting points for finding the way of reading the poetry of Fiama Hasse Pais Brandão and her fascination with hermeticism. In a second stage, this essay would like to propose, together with António Ramos Rosa, that the option for hermeticism is the central mark of contemporary poetry, which allows in consequence to recover that missing link between the poetry of Orpheu and that of the poets of the group Poesia 61 .

KEYWORDS: Fiama Hasse Pais Brandão, António Ramos Rosa, Árvore, hermetism, contemporary poetry.

\section{Este amor literal, o pormenor dos lábios, a aproximação da consciência é a situação mais nítida sobre a profundidade}

[dos gritos.

Fiama Hasse Pais Brandão. "A minha vida, a mais hermética". ${ }^{2}$

Pelo fio da memória lugares, vozes e situações nos revisitam, vindos de muito longe. Uma imagem em particular insiste em ficar. Encontramo-nos na Avenida Chile, antiga sede da Faculdade de Letras. Um jovem professor de literatura portuguesa dá início à aula ${ }^{3}$ Traz nas mãos uma nova apostila. A inscrição é breve: Poesia 61. Fiama, Luiza Neto Jorge, Maria Teresa Horta, Gastão Cruz, Casimiro de Brito despertam curiosidade entre os alunos e alunas da turma. Afinal, sabemos que em tempos sombrios, a poesia, com sua capacidade de "alterar o ângulo da visão", dissemina palavras através das metáforas, modo oblíquo e transferido do poeta dizer.

Corriam os anos 70. Com os autores, chegavam também os ecos da guerra colonial em África, a opressão salazarista em Portugal. Convém lembrar que do lado de cá do Atlântico, vivíamos também os chamados "anos de chumbo". Talvez por isso mesmo a descoberta de novíssimos poetas portugueses e africanos nos tenha resgatado a sensação partilhada por Octavio Paz: a de sermos, “pela primeira vez, contemporâneos de todos os homens”. (1976, p.14)

Num belíssimo livro, de se sua fase kantiana, o jovem Lukács nos adverte: “A nostalgia é sempre sentimental" para, em seguida, acrescentar:

Mas existem formas sentimentais? A forma é uma superação do sentimentalismo; na forma não há mais nostalgia nem solidão; as coisas se realizam plenamente ao se converterem em formas. Mas as formas da poesia são ainda temporais; sua realização pressupõe um "antes" e um "depois", não é um ser, mas um devir. O conceito de forma da poesia já não é um símbolo da nostalgia? (2011, p. 26)

No livro mencionado, o ensaísta húngaro tenta definir aquilo que se teria transformado no grande enigma a desafiar os teóricos da literatura: o da forma artística, o espaço para onde

2 BRANDÃO, Fiama Hasse Pais. Obra breve. Lisboa: Teorema, 1991, p. 201.

3 A referência é ao Professor Emérito Jorge Fernandes da Silveira, da Faculdade de Letras da UFRJ.

Diadorim, Rio de Janeiro, vol. 20, n. 1, p, 96-104, jan-jun. 2018. 
todos os possíveis se dirigem: o finito e o infinito, o eterno e o fugaz, a luz e a sombra, a vida e a morte, na aspiração pela unidade.

Foi a partir da imagem formulada por Lukács de que a forma seria uma espécie de tapete, onde as palavras comporiam os fios que engendrariam sua trama, que chegamos ao título: "Fiama Fiandeira: o fascínio pelo hermetismo". Uma outra voz se anuncia, acrescentando sentido acerca do nome da poeta: a de Eduardo Lourenço, "se a poesia é a palavra infinita que alude à matéria sem jamais a poder colher, a de Fiama, como um milagre, é a rosa mesma da realidade como uma chama, a que o seu nome mágico a predestinava."

Ainda pelo fio da memória, ecoa a de Eduardo Prado Coelho, quando numa de suas aulas, ${ }^{4}$ nos sugere um método de aproximação ao poema. A proposta consistia num mergulho profundo em suas águas, a fim de o investigar e apreender o que nele se ocultava. A lição dividia-se em três momentos. O primeiro, destinado à leitura dos visíveis do texto, a ideia inicial que a leitura desperta. O segundo, tendo "a palavra como isca", consistiria em captar os invisíveis do texto. Tratava-se de um processo de investigação delicado e minucioso, no qual caberia o registro das palavras que se repetiam, aquelas que se que opunham umas às outras, as que se que encontravam num processo de sinonímia, e, não menos importante, a descoberta da "palavra - maná", como a chamava Barthes ${ }^{5}$. A que funcionaria como um ímã, atraindo as demais. Tais palavras, como nos adverte Prado Coelho,

circulam no poema, arrumando e desarrumando sintagmas, intervindo em todos os lugares, de tal forma que o seu significado se reduz a um mínimo quase informulável, e o que predomina é a energia irradiante que de tais palavras se liberta, e que contagia toda a estrutura dos poemas, tornando-os expansivos e conferindo-lhes um máximo de abertura em relação ao real para que tendem. $(1979$, p. 211)

Finalmente, uma vez detectados os tais invisíveis, a etapa final consistiria em os articular. Uma vez articulados, estes invisíveis iriam formar os "novos" visíveis do texto. Seguindo a lição de Eduardo, e a de Jorge Fernandes da Silveira que como um toque de alerta defende a necessidade de uma rigorosa leitura, "rente ao texto", caminhamos em direção à poesia de Fiama Hasse Pais Brandão, seguindo, como nos lembra Valéry,

pela floresta encantada da linguagem, aquela em que os poetas entram expressamente para se perder, se embriagar de extravio, buscando as encruzilhadas de significação, os ecos imprevistos, os encontros estranhos; não temem os desvios, nem as surpresas, nem as trevas. (1983, p.12 e 13).

4 Curso de Mestrado, realizado nos Programas de Pós-Graduação, em Literatura Portuguesa, na Faculdade de Letras / UFRJ, em 1979, "O Neutro na Literatura".

5 Cf. BARTHES, Roland. Roland Barthes par Roland Barthes. Paris: Seuil, 1975, p. 133.

Diadorim, Rio de Janeiro, vol. 20, n. 1, p, 96-104, jan-jun. 2018. 


\section{Da fiandeira}

Iniciamos nossa aproximação, interminável como todo processo de aproximação, pelo poema, "Tapeçaria de Portalegre":
A contraluz as tecedeiras envoltas
numa aura intensa clara cruzam
e entrelaçam os fios inverossímeis.
Como poderão encontrar no meio da luz
fios senão os da própria luz
que está estendida? Postos assim,
quando vem o fim da tarde,
os teares contra as janelas velhas
de esquadria alta e ampla,
são os teares oníricos das pinturas
que tentam transformar a tecelagem
na metáfora da arte. (1991, p. 570)

Numa primeira incursão ao texto detectamos o sentido inicial do poema: o ofício (tecer) e o lugar (Portalegre), sintetizados no título: “Tapeçaria de Portalegre”. Os fios parecem ligar o ato (fiar, contemplar, escrever, quem sabe?) ao lugar. A fixação do lugar implica numa espécie de viagem, para o alcançar. Ainda uma vez Prado Coelho se faz presente: "Fiama viaja muito mais através do olhar que acompanha o rastro dos golfinhos nas águas prateadas do que através das viagens em que é preciso saltar os obstáculos das nações e das línguas”. 6

Seguindo a lição por ele anteriormente deixada - a busca dos invisíveis do texto -, duas repetições nos despertam atenção: a da palavra contra. O lugar onde as tecedeiras se encontram para exercer seu ofício, "contraluz", e os "teares" contra as janelas velhas. A palavra "contra" guardaria a ideia de adversidade, obstáculo, uma constante na poética de Fiama. A realização do trabalho em si cruza e entrelaça, se faz, mas com fios "inverossímeis".

Mas ali também se fixa a oposição claro / escuro, entre a objetividade e a subjetividade: "A contraluz", o local pouco iluminado, e "as tecedeiras envoltas / numa aura intensa clara". A ideia da aura, nos remete de modo inevitável a Walter Benjamin e seu comentário sobre a perda da aura da obra de arte, na era de sua reprodutibilidade técnica, quando a arte deixa de ser magia, perdendo o seu valor de culto, pelo de exposição. ${ }^{7}$

Em Fiama, confirmando Benjamin, ao contrário do produto industrial, o artesanato resgata a magia.

A luz estendida e o tapete estendido se confundem numa única imagem:

6 Cf. Eduardo Prado Coelho, Público, setembro de 2000.

7 Cf. Artigo de Walter Benjamin, "A obra de arte na era de sua reprodutibilidade técnica” publicado em 1955.

Diadorim, Rio de Janeiro, vol. 20, n. 1, p, 96-104, jan-jun. 2018. 
Como poderão encontrar no meio da luz

fios senão os da própria luz

que está estendida?

A dualidade temporal também se destaca. O poema tem início sob o signo da claridade (a manhã?) e avança para a noite que se avizinha. Os fios agora parecem tecer algo que aproxima o trabalho poético, com início e fim, ao ciclo da vida, ele também limitado por um antes e um depois.

\author{
Postos assim, \\ quando vem o fim da tarde, \\ os teares contra as janelas velhas.
}

Um outro tempo, imemorial, parece residir nas janelas "velhas". Mas se o ato de tecer é feito a contraluz, resgatando a imagem de uma caverna, um outro tear se apresenta contra as janelas velhas, onde as próprias janelas se transformam em outro tear, tão antigo quanto o tempo, aberto ao mundo exterior na pluralidade de seus espaços. Os teares, o lugar da produção da tecelagem, ocupam o centro da cena:

são os teares oníricos das pinturas que tentam transformar a tecelagem na metáfora da arte.

Há que se registrar o uso do verbo no presente para referir o fazer da tecelagem, indicando que a ação tende a se completar (“cruzam e entrelaçam”), ainda que sejam os fios inverossímeis, e o final do poema aponte para os teares oníricos das pinturas que "tentam" (o que não quer dizer que consigam) transformar a tecelagem na metáfora da arte.

Convém não esquecer que a figura das tecedeiras está associada à das fiandeiras do destino. A elas cabe tecer o futuro do homem e dos deuses num tear conhecido como a Roda da Fortuna. Elas o realizam num espaço de trevas e luz. Tal referência parece estar presente no poema de Fiama, quer no jogo claro / escuro por nós apontado anteriormente, quer nos teares contra as janelas velhas de esquadria alta e ampla, como se um tear estivesse dentro de outro tear, de um outro maior. Se os lugares na poesia de Fiama se destacam, se considerarmos que para ela o lugar da poesia, da palavra se funda ao derrubarmos obstáculos "onde / as mãos derrubam arestas / a palavra principia", talvez vislumbremos o sentido da "tecelagem como a metáfora da arte”. Pela arte, assegura-se a permanência. É no e pelo espaço simbólico que a dura Átropos e sua temível tesoura são vencidas.

Sabemos que a poesia de Fiama muda de pele ao longo do tempo, num processo de metamorfose constante. Ela se reescreve de modo contínuo. Assim, ainda uma vez, a figura da 
tecedeira irá reaparecer em sua obra, numa espécie de diálogo com "Tapeçaria de Portalegre".

Observemos o primeiro verso que dá nome ao poema:
Admiro a tecedora porque tem consentido
que a assemelhem à poesia.
mesmo com os cílios a perturbar-lhe
o movimento dos fios e os dedos
tocados por uma estranha resignação,
ela tece caudais líquidos
que escorrem na sensibilidade do poeta
desde que era criança. Aqueles
que não imaginaram na ceifeira de uhland
o cântico mais remoto da nova
ceifeira de fernando pessoa podem
agora começar a imaginá-lo. (1991, p. 306)

A primeira palavra "admiro", do verso inicial, contém outra dentro de si. Se eliminarmos as consoantes $-d$ e $r-\mathrm{e}$ a vogal $i$, temos amo. A Tecedora e o verbo amar ocultariam um nome, o de Fiama?

Três verbos marcam a relação do eu lírico com a tecedora: admirar, que irá reaparecer ao longo do poema por duas vezes: "Mas eu admiro/ sobretudo a injustiça para com / a tecedora, a de atribuir / aos seus dedos esfacelados / a incipiência do poema".

Em seguida, abjurar:

Eu abjuro da tecedora porque muitas vezes tem correspondido a quem lhe diz que a harpa produz estopa.

O poema tem início por zonas fronteiriças onde o trabalho da tecedora e o fazer poético se assemelhavam, numa estreita aliança. Pouco a pouco, tal harmonia se desfaz. E os termos lexicais se desagregam, "Ao chacoalhar/ todas as frases, os versos /caem uns dentro dos outros, e o poeta vê-se perante a impotência/ de os refazer sílaba a sílaba.” O poema parece articular os fios da criação poética e a inexorável passagem do tempo. Num estudo sobre (Este) Rosto, de Fiama, António Ramos Rosa parece ter definido as motivações que acompanham seu percurso poético: "a tensão que talvez se possa cifrar numa luta entre uma harmoniosa poética do espaço, e uma angustiante poética do tempo". (1971, pp. 88-89)

Nota-se ainda, no poema, uma passagem pelos elementos água, ar e fogo. Mantendo o mesmo jogo claro / escuro, Fiama recupera a poesia em suas fontes, da ceifeira de uhland, poeta do romantismo alemão, à modernidade de Pessoa. A presença da luz - "a metáfora da tecedora, 
até terminar / e recomeçar a teia, com o ritmo / passando a tempos regulares/ os fios obliquados pela luz" - nos remete ao conceito de pintura de Jackson Pollock, artista norte-americano: "Eu não pinto uma história, eu pinto a luz na parede". Dividido em três partes, o poema de Fiama parece descer às origens da poesia, confundida aí com a imagem da criança, numa espécie de processo genesíaco, no qual, com fina ironia, ratifica: "Mas eu admiro / sobretudo a injustiça para com/ a tecedora, a de atribuir aos seus dedos esfacelados / a incipiência do poema". Essa primeira parte conta com a presença do elemento água, que, segundo Bachelard, tudo sabe reunir. "Aqueles / que não imaginaram na ceifeira de uhland / o cântico mais remoto da nova / ceifeira de fernando pessoa podem / agora começar a imaginá-lo".

No segundo segmento do poema Fiama chama a crítica à cena onde o poema como produção mecânica exaltado por ela se opõe à idade do amor espontâneo e dos jorros do lirismo.

Por fim é com a imagem da tecedora ("só ela tem o privilégio de romper os fios pelo fogo" ) que o poema se fecha, inaugurando uma realidade incendiada.

\section{Do hermetismo: Onde buscar as raízes}

Casimiro de Brito, um dos poetas de Poesia 61, publicou versos do livro Duas águas um rio, que escrevera em parceria com o amigo António Ramos Rosa, no aniversário de sua morte. Traduzia de modo perfeito a história de uma amizade. ${ }^{8}$

Rosa foi um dos diretores da revista Árvore, Folhas de Poesia. No quarto e último número dessa publicação, em artigo por ele assinado - "A poesia é um diálogo com o universo" -, o poeta dá, a nosso ver, a chave de entendimento para o sentido da modernidade que Árvore pretendeu implementar na poesia portuguesa dos anos 50, enfrentando a questão, extremamente complexa, do caráter hermético da poesia. Rosa o compreende e defende. Sabe, por ofício, que o entendimento de "tal hermetismo define na sua linha mais geral a modernidade da poesia contemporânea". Tem ainda noção de que, para atingi-lo, é necessário o domínio dos segredos formais e de conteúdo. A noção de totalidade, a consciência desse anseio de totalidade fornecerá as bases teóricas de seu artigo. Assim é que talvez se localize em Árvore o elo perdido entre a geração de Orpheu e a Poesia $61^{9}$.

Nos fins dos anos 50, o escritor torna-se uma referência para os poetas que, no início da década seguinte, vão-se reunir em torno de Poesia 61. A influência de Ramos Rosa, pelo que se expôs, fora decisiva. Fiama, Gastão Cruz, Maria Teresa Horta, Casimiro de Brito estarão pre-

8 Cf. Cinda Gonda, "O que dizem as águas - a força de um diálogo: Casimiro de Brito e António Ramos Rosa". In: Poesia 61 hoje. Org. Jorge Fernandes da Silveira e Luís Maffei. Rio de Janeiro: Oficina Raquel, 2011, p. 43-54.

9 Cf. Gumercinda Nascimento Gonda, (Cinda Gonda). Árvore e o sentido da Modernidade (As mil maneiras de ver). Tese de doutorado. Faculdade de Letras da UFRJ, 2006.

Diadorim, Rio de Janeiro, vol. 20, n. 1, p, 96-104, jan-jun. 2018. 
sentes no último fascículo de Cadernos do Meio-Dia. Esse mantinha estreita ligação com Rosa em seu projeto editorial como por exemplo na coleção "A Palavra", inaugurada com Grito claro, de António Ramos Rosa, e onde também participaram Fiama e Luiza Netto Jorge. Convém lembrar que à mesma época, em 1962, surgirá Poesia liberdade livre.

A produção ensaística e estética - o arcabouço teórico que orientaria as novas tendências estéticas - constitui os laços que parecem unir Ramos Rosa e Fiama - a autonomia da arte, o seu hermetismo. No poema "Viagem através de uma nebulosa", Rosa segue pelas trilhas do surrealismo, onde o sonho e o inconsciente se transfiguram em luminosas metáforas. Em Fiama tais incursões surrealizantes comparecem em seu trabalho poético.

Talvez uma das constantes da poesia seja a formulação consciente ou inconsciente da síntese entre o contínuo e o descontínuo. A angústia da descontinuidade por vezes dá lugar a "momentos de eternidade".

Os meus poemas reunidos no seu todo

são o meu som. O meu sopro

está neles, não está a boca que os soou.

Fazer poemas, através da vida,

é pegar em meus gritos emudecidos

para que fiquem, melódicos em papéis (1991, p. 584)

O conjunto dos poemas de Fiama Hasse Pais Brandão atende por um nome: Obra breve. Nele podemos destacar a dualidade do título. Breve, se entendermos a vida como um pacto com o instante; e, paradoxalmente, "Breve", a mais longa das notações de tempo em linguagem musical, "gritos emudecidos para que fiquem melódicos em papéis".

Na introdução de seu livro Tempo e poesia, Eduardo Lourenço adverte que, em sentido radical, não há nada a dizer de um poema, pois é ele mesmo o dizer supremo e nos adverte: “o muro da linguagem e o muro da Caverna, o nosso mundo, são um só mundo. O melhor é descrevê-los, decifrá-los". (1974, pp. 25 e 26)

Fiama a mais sublime das fiandeiras, o faz. Através de uma poética onde se trançam a transparência e a opacidade, a luz e a sombra, na consciência dilacerante da finitude:

O sopro

Os meus poemas reunidos no seu todo

são o meu som. O meu sopro

está neles, não está a boca que os soou.

Fazer poemas, através da vida,

é pegar em meus gritos emudecidos

para que fiquem, melódicos, em papéis. (1991, p. 584). 
Referências:

BARTHES, Roland. Roland Barthes par Roland Barthes. Paris: Seuil, 1975.

BENJAMIN, Walter. Rua de mão dupla. Trad. João Barrento. Belo Horizonte: Editora da UFMG, 2010.

BRANDÃO, Fiama Hasse Pais. Obra breve. Lisboa: Teorema, 1991.

COELHO, Eduardo Prado. A letra litoral. Lisboa: Moraes, 1979.

COELHO, Eduardo Prado. “A escala do olhar”. Público. Lisboa, 02 de setembro de 2000.

GONDA, Cinda. "O que dizem as águas - a força de um diálogo: Casimiro de Brito e António Ramos Rosa”. In: Poesia 61 hoje. Org. Jorge Fernandes da Silveira e Luís Maffei. Rio de Janeiro: Oficina Raquel, 2011.

GONDA, Gumercinda. Árvore e o sentido da Modernidade (As mil maneiras de ver). Tese Doutorado. Programas de Pós-Graduação em Letras Vernáculas. Faculdade de Letras. 2006.

LOURENÇO, Eduardo. Tempo e poesia. Porto: Inova, 1974.

LUKÁCS, Georg. A alma e as formas. Intr. Judith Butler. Trad. Rainer Patriota. Belo Horizonte: Autêntica, 2015.

PAZ, Octávio. Poesía en movimiento. México: SigloVeintiuno, 1976.

ROSA, António Ramos. "Fiama Hasse Pais Brandão. (Este) Rosto". Crítica de Livros de Literatura Portuguesa. "Recensões Críticas". Colóquio Letras, nº 1 / março 1971.

ROSA, António Ramos. Poesia liberdade livre. Lisboa: Moraes, 1962. 